\title{
Cinacalcet therapy in patients affected by primary hyperparathyroidism associated to Multiple Endocrine Neoplasia Syndrome type 1 (MEN1)
}

\author{
Francesca Giusti ${ }^{1}$ - Luisella Cianferotti ${ }^{1}$ - Giorgio Gronchi ${ }^{1} \cdot$ Federica Cioppi $^{1}$ • \\ Laura Masi $^{1}$ - Antongiulio Faggiano ${ }^{2} \cdot$ Annamaria Colao $^{2} \cdot$ Piero Ferolla $^{3}$. \\ Maria Luisa Brandi ${ }^{1}$
}

Received: 11 March 2015/Accepted: 18 July 2015/Published online: 30 July 2015

(c) Springer Science+Business Media New York 2015

\begin{abstract}
Primary hyperparathyroidism is the main endocrinopathy associated with Multiple Endocrine Neoplasia type 1 syndrome. Cinacalcet is a calcimimetic agent licensed for the treatment of secondary hyperparathyroidism in patients with end-stage renal disease, and for the reduction of marked hypercalcemia in patients with parathyroid carcinoma and sporadic hyperparathyroidism requiring surgery but for whom parathyroidectomy is contraindicated. It may provide a medical alternative for the management of primary hyperparathyroidism in subjects affected by Multiple Endocrine Neoplasia type 1. In this longitudinal, intervention study, 33 MEN1 patients had been enrolled, 10 males and 23 females with a mean age of $40 \pm 11.9$ years, range 20-63. Primary hyperparathyroidism was the first clinical manifestation in 12 patients. All subjects commenced with Cinacalcet $30 \mathrm{mg} /$ day, 22 patients starting therapy with calcimimetics as an alternative to surgery, and 11 patients opting for the medication after the onset of persistent post-surgical primary hyperparathyroidism. Duration of follow-up was 12 months. The results of this study show significant reductions in serum calcium. The changes in hormonal secretions of pituitary and gastroenteropancreatic glands were not significant, demonstrating the overall safety of this drug in this disease. Cinacalcet has been well tolerated by 28 patients, whereas
\end{abstract}

Maria Luisa Brandi

marialuisa.brandi@unifi.it

1 Department of Surgery and Translational Medicine, University of Florence, Largo Palagi 1, 50139 Florence, Italy

2 Department of Clinical Medicine and Surgery, Federico II University, Naples, Italy

3 Department of Internal Medicine and Endocrine Sciences, University of Perugia, Perugia, Italy five individuals complained of heartburn and grade 1 nausea, which did not prevent the completion of the study. In conclusion, Cinacalcet has resulted to be well tolerated and safe in patients with MEN1 syndrome and the calcium homeostasis was stabilized.

Keywords Neuroendocrine tumor - PHPT - Pituitary tumor $\cdot$ Calcimimetic

\section{Introduction}

Primary hyperparathyroidism (PHPT) is the main endocrinopathy associated with MEN1 syndrome (MIM\#131100), occurring in more than $90 \%$ of affected individuals, with a penetrance reaching $100 \%$ within 50 years of age. PHPT in MEN1 is characterized by an age of onset between 20 and 25 years, which is three decades earlier than the age reported in the sporadic, non-syndromic, form of PHPT $(1,2)$. PHPT in MEN1 is generally supported by multiple parathyroid tumors with overproduction of parathyroid hormone (PTH) manifesting clinically with hypercalcaemia. Typically, it remains asymptomatic for a long time, or occurs with a reduction in bone mass at the age of 35 years $[1,2]$. The classical signs and symptoms related to chronic hypercalcaemia are present in MEN1 patients with lethargy, confusion, anorexia, nausea/vomiting, dieresis, dehydration, hypercalciuria, kidney stones, increased bone resorption and fracture risk, hypertension, and reduction in QT interval [3].

Neck surgery remains the elective care of symptomatic hypercalcemic PHPT in MEN1, although the optimum timing has not been defined $[2,4]$. Conventional open bilateral exploration with sub-total parathyroidectomy (at least 3.5 glands) or total parathyroidectomy is recommended and, 
autotransplantation may be considered [2,5], with relatively high risk of hypoparathyroidism and increased risk of laryngeal nerve damage [6].

Surgical approach for PHPT in MEN1 patients can be challenging because of the often-asynchronous multiglandular involvement and the possible presence of supernumerary and ectopic parathyroid glands, with high persistence/recurrence rate [4]. For these reasons, a pharmacological approach in early-diagnosed MEN1 patients with PHPT would certainly be appropriate.

The calcium-sensing receptor (CaSR) is prominently expressed in the parathyroid gland and the kidney, but it is also expressed in many other organs and participates in the regulation of a variety of processes such as fluid and ion transport, cellular proliferation, differentiation and apoptosis, and hormone secretion other than the regulation of PTH secretion and renal calcium handling [7].

The type II calcimimetics such as Cinacalcet (Sensipar ${ }^{\circledR}$ in North America and Australia, Mimpara ${ }^{\circledR}$ in Europe) are compounds which bind the CaSR and increase its sensitivity to extracellular calcium, thus reducing serum levels of PTH and calcium [8-12]. Multicenter, randomized, double-blind, placebo-controlled trials have shown the ability of Cinacalcet to achieve long-term reductions in serum concentrations of PTH and calcium concentrations in patients with sporadic PHPT and the efficacy of this drug in controlling the diseases in a subgroup of patients with PHPT and contraindications to surgery [13, 14]. Cinacalcet is approved for treatment of SHPT in patients with endstage renal disease or maintenance dialysis therapy, for the treatment of hypercalcemia in patients with parathyroid carcinoma, and in patients with PHPT for whom parathyroidectomy would be indicated on the basis of serum calcium levels according to published guidelines, but not clinically appropriate for associated problems [15, 16]. Besides the proven efficacy of this drug, both FDA and EMA have recently stated that Cinacalcet "is not indicated for the use in children and adolescents due to the lack of data on safety and efficacy," because of a serious adverse event (deadly hypocalcemia) in one case [17, 18]. More recently, Cinacalcet has been suggested as an alternative treatment for patients who do not meet the criteria for parathyroidectomy, or for those who failed a previous parathyroidectomy $[19,20]$.

To date, there is little clinical experience on the use of Cinacalcet in hereditary forms of PHPT, in which a genetically determined susceptibility to the growth of abnormal parathyroid tissue is already present at birth, and information on the effect of the drug on growth and function of parathyroid tissue is limited [21, 22].

After an initial promising experience in a 30-year-old MEN1 patient [21], a prospective audit and a randomized, double-blind, cross-over trial has been carried out in small group of young MEN1 patients [22, 23]. These studies confirmed the short-term efficacy and safety of Cinacalcet in MEN1-related PHPT [23]. A larger Italian multicenter retrospective study on the clinical use of Cinacalcet in patients with PHPT, which also included familial forms of this disease, confirmed that the drug effectively reduced serum calcium in all patients, with no significant change in PTH levels as compared to the baseline data [24]. Interestingly, this study showed that the European Medicines Agency (EMA) label for Cinacalcet prescription is not always followed, particularly in patients with familial forms of the disease, in which younger patients with PHPT are prevalent.

Similar to what has been observed with the well-standardized dopamine agonist drugs in the treatment of hyperprolactinemia in patients with MEN1, the Cinacalcet could help avoid/reduce parathyroid surgery in these subjects, together with post-surgical complications such as chronic hypoparathyroidism [2].

A study to test the efficacy, safety, and tolerability of treatment with Cinacalcet in a group of adult patients with MEN1-related PHPT was therefore undertaken, aiming to evaluate whether this calcimimetic can be considered as an acceptable medical treatment in MEN1-PHPT.

\section{Patients and methods}

\section{Study design}

This is a multicenter, phase IV, prospective, open-label, non-comparative trial in patients with MEN1-PHPT of both sexes, aged $>18$ years, with normal liver and kidney function, who were selected to receive Cinacalcet (30 mg/day orally, or more, up to a maximum of $60-90 \mathrm{mg} /$ day in the case of inadequate response to the previous dose) for a period of 12 months, with possible extension to 24 months. An interim analysis at 6 months was planned to assess whether the treatment was effective in more than 6 patients, which allowed the study to continue up to 12 months, with the aim of considering only patients completing the 12-month follow-up at an adequate dose of Cinacalcet for the analysis of its efficacy. Thus, in the intention to treat, subjects who were not compliant to treatment, and/or who developed adverse effects preventing Cinacalcet dose adjustment for the control of hypercalcemia, were excluded from the analysis of efficacy.

The primary objective of this study was to assess the effect of Cinacalcet on serum calcium and PTH levels. Secondary objectives were to analyze the changes in bone turnover markers, bone mineral density, neuroendocrine MEN1-related hormones, parathyroid size, and safety and tolerability of Cinacalcet. 


\section{Patients}

A program of biochemical screening for parathyroid lesions in adult patients (age $\geq 18$ years) with MEN1 included assessment of fasting, circulating total calcium, and PTH. Patients with a diagnosis of MEN1, as confirmed by history and/or genetic testing, were considered eligible for the study if showing PHPT, as evidenced by serum PTH $>72.4 \mathrm{pg} / \mathrm{mL}$ (or $7.6 \mathrm{pmol} / \mathrm{mL}$ ) and total corrected serum calcium $>10.3 \mathrm{mg} / \mathrm{dL}$ (or $>2.57 \mathrm{mmol} / \mathrm{L}$ ) and/or ionized calcium at $\mathrm{pH} 7.4>5.3 \mathrm{mg} / \mathrm{dL}$. These subjects refused surgery or had comorbidities or displayed contraindications for re-intervention in the case of persistent/recurrent PHPT after sub-total/total parathyroidectomy. Inclusion criteria were a good performance status (Eastern Cooperative Oncology Group-ECOG-score $\leq 2$ ) and normal liver and kidney function.

Patients were recruited and evaluated during the period 2009-2013 in three different University Centers (University Hospitals of Florence, Naples, and Perugia). The subjects enrolled for this study were not included in other previously published retrospective studies. The study was authorized by the local Internal Review Boards, and was registered with the EudraCT (European Clinical Trials) Database as 2009-009502-79. This study was conducted in accordance with the Declaration of Helsinki, and written informed consent was obtained from all the participating patients. Cinacalcet was provided free of charge even to patients not meeting the EMA criteria for the administration of Cinacalcet, taking advantage of special Regional Acts for Rare Diseases and Orphan Drugs.

A total of thirty-three patients with MEN1-PHPT (10 M and $23 \mathrm{~F}$, with a mean age of $40 \pm 11.9$ years, range 20-63) were considered eligible and therefore enrolled in the study in the period of 2009-2012. Twenty subjects were enrolled in Florence, twelve in Naples, and one in Perugia.

Twenty-two patients accepted initiating therapy with Cinacalcet as an alternative to surgery, because they had MEN1-related comorbidities for which surgery was contraindicated (such as VIPoma), or they refused or postponed surgery for personal reasons. Eleven patients had persistent or recurrent PHPT after sub-total or total parathyroidectomy (7 and 4 patients, respectively) with contraindications for re-intervention.

Patients were evaluated with serum calcium and PTH determinations at baseline, and, after a 1-month titration period for dose individualization, at 6 and 12 months.

The response to treatment was interpreted as complete when serum calcium and/or PTH normalized, and partial when serum calcium and/or PTH decreased more than $5 \%$ without falling within the normal range. $\mathrm{A}<5 \%$ drop or an increase in serum calcium and PTH pointed toward disease persistency or progression, respectively.

\section{Genetic analyses}

The diagnosis of MEN1 was completed by genetic testing. All patients had undergone a MEN1 gene analysis after providing appropriate informed consent.

From each patient, a blood sample was collected, genomic DNA was extracted, and all protein-coding regions of exons 2 through 10 of the MEN1 gene were amplified using polymerase chain reaction (PCR). PCR assay and sequence analyses were performed.

Multiplex ligation-dependent probe amplification (MLPA) was performed in patients in whom no mutation was found, to screen for large deletions in the MEN1 gene, since PCR-based sequence analysis for mutation detection is not able to detect a large monoallelic deletion.

\section{Biochemical measurements and hormonal profile}

Blood samples for the measurement of total serum calcium, PTH, and gastroenteropancreatic (chromogranin A, gastrin, pancreatic polypeptide (PP), vasoactive intestinal polypeptide (VIP), insulin, glucagon) and pituitary (PRL, IGF1) hormones were collected after an overnight fast, before morning drug administration; in the case with replanting parathyroid tissue fragments in the non-dominant forearm, a sample from forearm without the transplant was drawn. Venous blood samples were collected in tubes containing EDTA and Trasylol (5000 KIU Trasylol in $10 \mathrm{~mL}$ vacutainer). The samples were cooled in an ice bath immediately.

Biochemical and hormonal measurements were centralized in Florence.

Serum calcium concentrations were measured by an automated colorimetric method (ADVIA $2400^{\circledR}$ Chemistry System, Siemens, Germany; intraassay precision of $2.0 \%$ and interassay precision of $2.2 \%$ at $9.9 \mathrm{mg} / \mathrm{dL}$; intraassay precision of $1.9 \%$ and interassay precision of $2 \%$ at $14 \mathrm{mg} / \mathrm{dL}$ ). Plasma concentrations of PTH were determined by using a commercially available chemiluminescent immunoassay (ADVIA Centaur ${ }^{\circledR}$ Immunoassay System, Siemens, Germany; intraassay precision of $5.2 \%$ and interassay precision of $5.8 \%$ at $40.4 \mathrm{pg} / \mathrm{mL}$; intraassay precision of $3.4 \%$ and interassay precision of $1.5 \%$ at $223.8 \mathrm{pg} / \mathrm{mL}$ ). Normal ranges for serum calcium and plasma PTH were $8.2-10.3 \mathrm{mg} / \mathrm{dL}$ and $20-72.4 \mathrm{pg} / \mathrm{mL}$, respectively.

Bone-specific alkaline phosphatase (BALP), as bone formation marker, was determined by ELISA (Immunodiagnostic Systems Ltd, IDS, Frankfurt, Germany). A fasting 
second morning urine sample was collected to measure urinary deoxypiridinoline as resorption marker by chemiluminescent immunometric assay (Immulite 2000, DPD, Diagnostic Products Corporation, Los Angeles, CA, USA); results were expressed as urinary DPD/creatinine ratio (UrDPD/Cr). Normal ranges for BALP were 7-20.1 $\mu \mathrm{g} / \mathrm{L}$ for men, $4-14.3 \mu \mathrm{g} / \mathrm{L}$ for premenopausal women, and 6-22.5 $\mu \mathrm{g} / \mathrm{L}$ for postmenopausal women. Normal range for $\mathrm{UrDPD} / \mathrm{UrCr}$ was $3-7.4 \mathrm{nmol} / \mathrm{mmol}$.

Other biochemical and hormonal analytes and their normal range are herein reported: ionized calcium $4.3-5.3 \mathrm{mg} /$ $\mathrm{dL}$, chromogranin A $10-185 \mathrm{ng} / \mathrm{mL}$, gastrin $<108 \mathrm{pg} / \mathrm{mL}$, $\mathrm{PP}<100 \mathrm{pg} / \mathrm{mL}$, VIP $<31 \mathrm{pg} / \mathrm{mL}$, glucagon $<250 \mathrm{pg} / \mathrm{mL}$, insulin 3-17 mU/L, PRL 72-504 mU/L, insulin-like growth factor-1 (IGF-1) 116-358 ng/mL, ACTH 9-52 ng/L.

Hormonal profiles, bone turnover markers, bone densitometry, and parathyroid size were assessed at 12 months of Cinacalcet administration.

\section{Bone mineral density}

Bone densitometry, which is considered the gold standard in the investigation of bone mineral density (BMD), was performed at the lumbar spine and proximal femur (femoral neck) by dual-energy x-ray absorptiometry (DXA) using a Hologic Delphi A densitometer (Hologic, Inc., Waltham, MA, USA) in Florence (for patients evaluated in Florence and Perugia) and a Hologic Discovery densitometer (Hologic, Inc., Waltham, MA, USA) in Naples (for patients evaluated in Naples). The coefficients of variation were $1.09-1.09 \%$ for the spine and $1.4-1.3 \%$ for the total hip. Cross-calibration coefficients ranged from 0.85 to 1.14.

BMD values were expressed in absolute BMD $\left(\mathrm{g} / \mathrm{cm}^{2}\right)$, $\mathrm{T}$-score and Z-score values.

BMD was assessed at baseline and after 12 months of Cinacalcet administration, on the same densitometer for each patient.

\section{Neck ultrasound and parathyroid scintigraphy}

Parathyroid growth and function were evaluated with neck ultrasound and parathyroid scintigraphy at baseline and after 12 months of Cinacalcet administration. One patient did not have an ultrasound performed at 12 months, and two patients did not have the parathyroid scintigraphy at 12 months because they refused.

\section{Statistical analysis}

Data were expressed as a percentage, mean with standard deviation (three single determinations for serum calcium), and median with interquartile range (three single determinations for serum PTH, which is non-normally distributed). In the intention-to-treat study, only patients who continued Cinacalcet therapy for at least 12 months at an adequate dose (i.e., proper dose adjustment along the follow-up) would have been considered for the analysis of efficacy. A one-way ANOVA for repeated measures was used to evaluate the changes in serum calcium levels versus baseline, while a Student's $t$ test was applied to the analysis of pituitary and gastroenteropancreatic hormones and bone mineral density. A non-parametric test for dependent measures (Friedman test) was employed to evaluate the changes in serum PTH levels versus baseline. In all cases $p<0.05$ was considered significant.

\section{Results}

The baseline clinical characteristics, MEN1-related genetic alterations and the main biochemical data before and after cinacalcet treatment are reported in Table 1 .

\section{Clinical presentation}

PHPT was the first manifestation of MEN1 in the majority of patients, namely in \#19 patients (58\%). Seven patients (21\%) had symptomatic PHPT (e.g., history of kidney stones); in \#12 patients (37\%) PHPT was asymptomatic and diagnosed during biochemical screening (Fig. 1).

The first manifestation of MEN1 was prolactinoma in \#5 patients $(15 \%)$, peptic ulcer in \#4 patients $(12 \%)$, acromegaly in \#1 patient ( $3 \%$ ), hypoglycemia in \#1 patient (3\%), VIPoma in \#1 patient (3\%), headache in \#1 patient $(3 \%)$, and non-functioning gastroenteropancreatic neuroendocrine tumor (GEP-NET) in \#1 patient (3\%) (Fig. 1). All the patients were diagnosed with PHPT as confirmed by hypercalcaemia and elevated or inappropriately elevated serum PTH levels.

\section{Genetics}

Twenty-seven patients were familial cases resulting from nineteen families, whereas six patients were simplex cases. In twenty-five familial cases and in three simplex cases we identified a mutation in the MEN1 gene; in particular, in one family, a double mutation was detected, while in one family and in three simplex cases, no MEN1 mutations were found. In one family (two subjects) negative for MEN1 mutations, MLPA analysis showed a large deletion in chromosome 11q13.1 encompassing MEN1 locus. 
Table 1 Baseline clinical characteristics of the \#33 patients, genetic alterations, and main biochemical data before and after cinacalcet treatment

\begin{tabular}{|c|c|c|c|c|c|c|c|c|}
\hline & $\begin{array}{l}\text { Age } \\
\text { (years) }\end{array}$ & Sex & MEN1 mutation & Form $^{\mathrm{a}}$ & $\begin{array}{l}\text { MEN1-related manifestations } \\
\text { (other than PHPT) }\end{array}$ & Osteoporosis $^{\mathrm{b}}$ & Nephrolithiasis & $\begin{array}{l}\text { Previous } \\
\text { PTX }\end{array}$ \\
\hline 1 & 23 & $\mathrm{~F}$ & No & Familial & No & Yes & No & No \\
\hline 2 & 56 & $\mathrm{~F}$ & No & Familial & PRLoma gastrinoma & No & Yes & Sub-total \\
\hline 3 & 50 & M & Missense. Glu45Gln. exon 2 & Familial & VIPoma. PRLoma & No & No & No \\
\hline 4 & 33 & $\mathrm{~F}$ & Frameshift. 1433del6(GCAGTC) & Familial & PRLoma & No & No & Total \\
\hline 5 & 23 & M & Nonsense. Arg415Stop. exon 9 & Familial & PRLoma & Yes & No & No \\
\hline 6 & 20 & $\mathrm{~F}$ & Nonsense. Arg415Stop. exon 9 & Familial & PRLoma & No & No & No \\
\hline 7 & 56 & M & Nonsense. Arg415Stop. exon 9 & Familial & PRLoma & Yes & No & Total \\
\hline 8 & 44 & M & Missense. Asp418Asn. exon 9 & simplex & Bronchial carcinoid. PRLoma & No & No & No \\
\hline 9 & 41 & $\mathrm{~F}$ & Frameshift. 1364delC. exon 9 & Familial & $\begin{array}{l}\text { PRLoma. bronchial carcinoid. } \\
\text { insulinoma. lipoma }\end{array}$ & No & No & Total \\
\hline 10 & 40 & $\mathrm{~F}$ & Frameshift. 1690delG. exon 10 & Familial & $\begin{array}{l}\text { VIPoma } \\
\text { PRLoma }\end{array}$ & No & No & Sub-total \\
\hline 11 & 39 & $\mathrm{~F}$ & Frameshift. 1555ins. exon 10 & Familial & PRLoma & No & Yes & Total \\
\hline 12 & 44 & $\mathrm{~F}$ & $\begin{array}{l}\text { Splicing 935-2 }(\mathrm{A}>\mathrm{G}) \text { introne } \\
\text { 5-exon } 6\end{array}$ & simplex & PRLoma. lipoma & Yes & No & No \\
\hline 13 & 63 & M & $\begin{array}{l}\text { Missense. Leu249Pro.esone4 } \\
\text { Frameshift.1181del. exon } 8\end{array}$ & Familial & PRLoma. gastrinoma & No & No & No \\
\hline 14 & 37 & $\mathrm{~F}$ & $\begin{array}{l}\text { Missense. Leu249Pro. exon } 4 \\
\text { Frameshift. 1181del. exon } 8\end{array}$ & Familial & PRLoma & No & No & No \\
\hline 15 & 24 & M & Frameshift. $317 \mathrm{delC}$ exon 2 & Familial & PRLoma & Yes & No & No \\
\hline 16 & 32 & $\mathrm{~F}$ & Frameshift. 738 del 4 exon 3 & Familial & Insulinoma & No & No & No \\
\hline 17 & 51 & $\mathrm{~F}$ & Missense LEU168PRO exon 3 & Familial & Non-functioning GEP-NET & No & No & No \\
\hline 18 & 30 & $\mathrm{~F}$ & $\begin{array}{l}\text { Splicing894-9 }(\mathrm{G}>\mathrm{A}) \text { intron } \\
\text { 4-exon } 5\end{array}$ & simplex & $\begin{array}{l}\text { Non-functioning pituitary } \\
\text { macroadenoma. non- } \\
\text { functioning GEP-NET }\end{array}$ & No & No & Sub-total \\
\hline 19 & 48 & $\mathrm{~F}$ & No & Familial & Gastrinoma & Yes & No & No \\
\hline 20 & 40 & M & $\begin{array}{l}\text { Splicing. } 1159+1(\mathrm{G}>\mathrm{A}) \text { intron } \\
\quad \text {-exon } 7\end{array}$ & Familial & $\begin{array}{l}\text { Non-functioning GEP-NET. } \\
\text { macroPRLoma }\end{array}$ & No & Yes & Sub-total \\
\hline 21 & 60 & $\mathrm{~F}$ & Frameshift. 1671 del 11 exon 10 & Familial & Gastrinoma & Yes & No & No \\
\hline 22 & 24 & $\mathrm{~F}$ & NO & simplex & PRLoma & No & Yes & Sub-total \\
\hline 23 & 49 & $\mathrm{~F}$ & $\begin{array}{l}\text { Splicing. 765-1(AG }>A C) \text {. intron } \\
\text { 3-exon } 4\end{array}$ & Familial & Non-functioning GEP-NET & No & No & No \\
\hline 24 & 44 & $\mathrm{~F}$ & Frameshift. 468delAAG exon 2 & Familial & Gastrinoma & No & Yes & No \\
\hline 25 & 33 & M & Frameshift. 1671del11 exon 10 & Familial & $\begin{array}{l}\text { GHoma; non-functioning } \\
\text { GEP-NET }\end{array}$ & No & No & No \\
\hline 26 & 39 & M & Frameshift. 1061delC exon 7 & Familial & Non-functioning GEP-NET & No & No & No \\
\hline 27 & 49 & $\mathrm{~F}$ & Frameshift. $317 \mathrm{delC}$ exon 2 & Familial & $\begin{array}{l}\text { Gastrinoma. Non-functioning } \\
\text { pituitary adenoma }\end{array}$ & Yes & No & No \\
\hline 28 & 23 & $\mathrm{~F}$ & Frameshift. 317delC exon 2 & simplex & Non-functioning GEP-NET & Yes & No & No \\
\hline 29 & 54 & $\mathrm{~F}$ & Frameshift. 1061delC exon 7 & Familial & $\begin{array}{l}\text { Non-functioning GEP-NET. } \\
\text { Non-functioning pituitary } \\
\text { adenoma }\end{array}$ & No & Yes & Sub-total \\
\hline 30 & 29 & $\mathrm{~F}$ & Frameshift. 1671del11 exon 10 & Familial & $\begin{array}{l}\text { PRLoma. Non-functioning } \\
\text { GEP-NET }\end{array}$ & Yes & No & Sub-total \\
\hline 31 & 52 & M & Frameshift. $317 \mathrm{delC}$ exon 2 & Familial & $\begin{array}{l}\text { PRLoma. Non-functioning } \\
\text { GEP-NET }\end{array}$ & No & No & No \\
\hline 32 & 35 & $\mathrm{~F}$ & NO & simplex & $\begin{array}{l}\text { PRLoma. Non-functioning } \\
\text { GEP-NET }\end{array}$ & No & Yes & No \\
\hline 33 & 31 & $\mathrm{f}$ & $\begin{array}{l}\text { Frameshift. } \\
\text { 1671del11(ACTGTCGCTGG). } \\
\text { exon } 10\end{array}$ & Familial & No & Yes & No & No \\
\hline
\end{tabular}


Table 1 continued

\begin{tabular}{|c|c|c|c|c|c|c|c|c|}
\hline & $\begin{array}{l}\text { Number of } \\
\text { glands removed }\end{array}$ & Implant & $\begin{array}{l}\mathrm{Ca}(\mathrm{mg} / \mathrm{dL}) \\
\text { at baseline }\end{array}$ & $\begin{array}{l}\mathrm{Ca}(\mathrm{mg} / \mathrm{dL}) \text { at } \\
+12 \text { months }\end{array}$ & $\begin{array}{l}\mathrm{Ca}^{++}(\mathrm{mg} / \mathrm{dL}) \\
\text { at baseline }\end{array}$ & $\begin{array}{l}\mathrm{Ca}^{++}(\mathrm{mg} / \mathrm{dL}) \text { at } \\
+12 \text { months }\end{array}$ & $\begin{array}{l}\mathrm{PTH}(\mathrm{mg} / \mathrm{dL}) \\
\text { at baseline }\end{array}$ & $\begin{array}{l}\text { PTH }(\mathrm{mg} / \mathrm{dL}) \text { at } \\
+12 \text { months }\end{array}$ \\
\hline 1 & - & - & 11.4 & 8.8 & 6.0 & 5.2 & 75.5 & 54.3 \\
\hline 2 & $3+1 / 2$ & - & 10.1 & 10.1 & 5.9 & 5.3 & 132.4 & 61.9 \\
\hline 3 & - & - & 9.9 & 10 & 5.7 & 5.4 & 584.8 & 185.0 \\
\hline 4 & 4 & No & 9.9 & 8.9 & 5.5 & 5.2 & 199.0 & 94.3 \\
\hline 5 & - & - & 11 & 10 & 5.6 & 5.2 & 75.0 & 84.8 \\
\hline 6 & - & - & 10.2 & 9.8 & 5.4 & 5.2 & 83.8 & 85.8 \\
\hline 7 & 4 & Yes & 10.6 & 9.7 & 5.8 & 5.1 & 103.8 & 402.0 \\
\hline 8 & - & - & 10.5 & 9.3 & 5.8 & 5.0 & 247.6 & 105.5 \\
\hline 9 & 4 & Yes & 10.8 & 9.3 & 5.4 & 4.9 & 100.0 & 75.2 \\
\hline 10 & 3 & - & 10.8 & 10.5 & 5.7 & 5.3 & 247.0 & 184.8 \\
\hline 11 & 4 & Yes & 10.5 & 10.5 & 6.0 & 6.0 & 108.6 & 106.7 \\
\hline 12 & - & - & 10.9 & 9.8 & 6.1 & 5.1 & 140.9 & 112.4 \\
\hline 13 & - & - & 10.7 & 10.5 & 6.0 & 5.3 & 184.8 & 234.0 \\
\hline 14 & - & - & 9.9 & 8.8 & 5.4 & 4.8 & 152.4 & 117.1 \\
\hline 15 & - & - & 11.8 & 9.8 & 5.9 & 4.9 & 78.6 & 45.5 \\
\hline 16 & - & - & 11.4 & 10 & 5.7 & 5.1 & 227.0 & 452.0 \\
\hline 17 & - & - & 11.1 & 10.9 & 5.7 & 5.6 & 277.0 & 175.0 \\
\hline 18 & 1 & - & 11.3 & 9.9 & 6.1 & 5.2 & 165.0 & 110.0 \\
\hline 19 & - & - & 12.5 & 10 & 6.4 & 4.9 & 707.0 & 948.0 \\
\hline 20 & 1 & - & 10.6 & 9.8 & 5.4 & 4.6 & 81.5 & 94.5 \\
\hline 21 & - & - & 11.9 & 10.3 & 6.2 & 5.4 & 108.0 & 145.0 \\
\hline 22 & 2 & - & 10.6 & 8.5 & 5.5 & 4.5 & 94.3 & 103.0 \\
\hline 23 & - & - & 11 & 10.3 & 6.1 & 5.7 & 178.0 & 152.0 \\
\hline 24 & - & - & 11.2 & 9.2 & 5.7 & 5.1 & 305.0 & 259.0 \\
\hline 25 & - & - & 11.1 & 10.3 & 6.1 & 5.4 & 257.0 & 142.0 \\
\hline 26 & - & - & 10.3 & 10.1 & 5.7 & 5.0 & 146.0 & 152.0 \\
\hline 27 & - & - & 11.8 & 10 & 5.9 & 4.9 & 178.0 & 135.0 \\
\hline 28 & - & - & 11 & 10.1 & 5.9 & 4.8 & 77.9 & 130.0 \\
\hline 29 & 1 & - & 10.3 & 9.3 & 5.5 & 4.7 & 77.0 & 138.0 \\
\hline 30 & 3 & - & 10.5 & 9.8 & 5.7 & 4.8 & 89.0 & 70.0 \\
\hline 31 & - & - & 10.3 & 10 & 5.4 & 5.2 & 104.0 & 72.6 \\
\hline 32 & - & - & 11.1 & 10.4 & 6.0 & 5.7 & 89.9 & 141.0 \\
\hline 33 & - & - & 11.2 & 10.2 & 5.9 & 5.1 & 178 & 204.0 \\
\hline
\end{tabular}

The patients excluded from the analysis of efficacy (see "Results" section) are identified by numbers written in italic and bold (\#5, \#11, \#18, \#26, \#33)

$P R L$ prolactinoma, $\mathrm{Ca}$ serum corrected total calcium, $\mathrm{Ca}^{++}$serum ionized calcium

a Simplex form $=$ only one affected individual without evidence of a positive familial history; familial form = MEN1 syndrome in an individual who has either at least one first-degree relative with at least one of the main endocrine tumors or only one organ involvement and a MEN1 disease-causing germline mutation

b $\mathrm{T}$-score $<-2.5$ in at least one measured site

\section{Biochemical measurements and hormonal profile}

\section{Serum and urinary calcium and serum PTH}

At baseline, all the \#33 patients showed increased serum PTH levels (median 141.0, interquartile range 123.55, range
75.0-707), \#28 patients showed elevated serum calcium levels (average $10.8 \pm 0.6 \mathrm{mg} / \mathrm{dL}$, range 9.9-12.5). In the \#5 patients $(15.1 \%)$ who displayed a total serum calcium value in the high-normal range, ionized calcium was increased (Table 1). Twenty-one patients $(63.6 \%)$ had mild hypercalcemia (i.e., serum calcium within $1 \mathrm{mg} / \mathrm{dL}$ above 


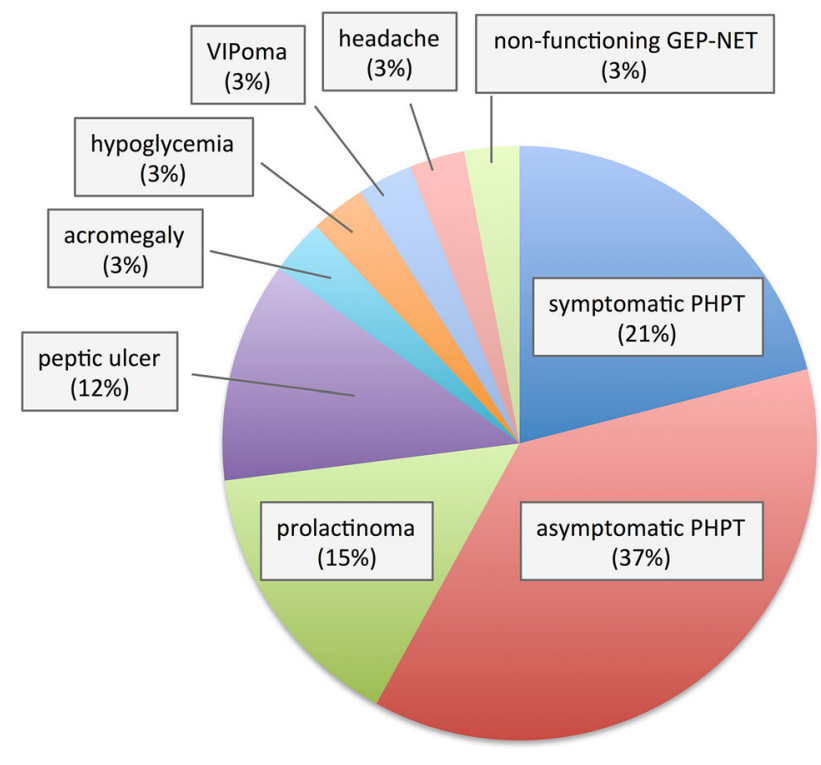

Fig. 1 Initial clinical manifestation of the \#33 patients with MEN1 undergoing Cinacalcet treatment

the upper limit of the reference range), while 7 patients $(21.2 \%)$ had marked hypercalcemia.

All patients began daily treatment with Cinacalcet $30 \mathrm{mg}$, with the indicated monitoring of serum total and ionized calcium. In the majority of patients (\#17, 51.5\%), Cinacalcet was maintained with a daily dosage of $30 \mathrm{mg}$ for the duration of the study, while the dosage was increased up to $60 \mathrm{mg} /$ day ( $30 \mathrm{mg}$ twice daily) in fifteen patients $(45.5 \%)$ and up to $90 \mathrm{mg} /$ day in one patient (30 mg 3 times/day) in the follow-up period, due to persistence/relapse of hypercalcaemia.

All patients completed the 12-month study, and withdrawal from the drug was not necessary for anyone. However, in $5(15 \%)$ of the 33 enrolled subjects, the required upward dose adjustment at 6 months was not possible because of heartburn and grade 1 nausea (i.e., not leading to altered eating or mild vomiting). For this reason, these individuals were excluded from the analysis of efficacy, as previously stated.

After just 6 months of Cinacalcet administration, a mean significant $8.3 \%$ decrease in serum calcium $(9.9 \mathrm{mg} /$ $\mathrm{dL}$ at 6 months vs. $10.9 \mathrm{mg} / \mathrm{dL}$ at baseline, $p<0.001$ ) was observed (Fig. 2). In particular, the reduction appeared to be $9.3 \%$ in patients treated with $30 \mathrm{mg} /$ day of Cinacalcet, $7.9 \%$ in patients receiving $60 \mathrm{mg} / \mathrm{day}$, and $3,8 \%$ in the patient treated with $90 \mathrm{mg} /$ day. A dose adjustment (increase to $60 \mathrm{mg}$ ) at 6 months was necessary in 6 patients to control hypercalcemia.

After 12 months of Cinacalcet treatment, an average decreased value of serum calcium by $9.5 \%$ was observed $(9.8 \mathrm{mg} / \mathrm{dL}$ at 12 months vs. $10.9 \mathrm{mg} / \mathrm{dL}$ at baseline, $p<0.001)$. In particular, the reduction appeared to be similar in the groups treated with 30 and $60 \mathrm{mg} /$ day $(9.1$ and $9.9 \%$, respectively), and $11.4 \%$ in the patient treated with $90 \mathrm{mg} / \mathrm{day}$.

A complete response (i.e., normalization of serum calcium levels) was observed in 22/28 (78.5\%) patients at 6 months and up to $25 / 28$ patients $(89.3 \%)$ at 12 months, a partial response (i.e., decrease in serum calcium levels $>5 \%$ without normalization) in $4 / 28(14.3 \%)$ at 6 months and only in $1 / 28(3.6 \%)$ at 12 months, a disease persistency (i.e., decrease in serum calcium levels $0-5 \%$ ) in $1 / 28(3.6 \%)$ at 6 months and in $2 / 28(7.1 \%)$ at 12 months, while a disease progression (i.e., increase in serum calcium levels) was observed only in 1 individual at 6 months, who eventually showed normocalcemia at 12 months. In patients in whom hypercalcemia was not completely controlled at 12 months, a further adjustment of the dosage after the completion of the study was able to normalize serum calcium levels (data not shown).

No statistical significant difference in terms of response to Cinacalcet between the group of patients who received cinacalcet as primary treatment and the group of those with persistence or recurrent disease after surgery.

It is worth noting that in $4 / 5$ individuals excluded from the intention-to-treat analysis, who showed mild hypercalcemia at 6 months (mean serum calcium $10.1 \mathrm{mg} / \mathrm{dL}$ ), and in whom dose adjustment was not feasible because of side effects, serum calcium spontaneously normalized under $30 \mathrm{mg} / \mathrm{d}$ of Cinacalcet at the end of the 12-month follow-up period.

No significant changes in urinary calcium excretion or serum PTH levels were observed under Cinacalcet administration. With respect to PTH, at 6 and 12 months, modest, non-significant decreases in serum PTH versus baseline were detected (median values $117.7 \mathrm{pg} / \mathrm{mL}$, interquartile range 119.5, at 6 months and $136.5 \mathrm{pg} / \mathrm{mL}$ at

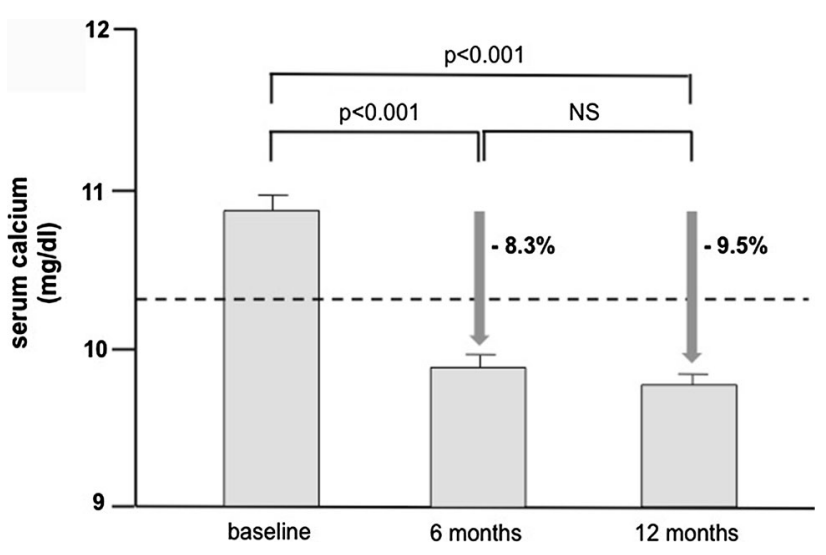

Fig. 2 Changes in the mean serum calcium levels and relative percentual change at 0,6 months, and 12 months of Cinacalcet treatment in \#33 MEN1 patients (NS non-significant) 
12 months, interquartile range 90.6 vs. $146.7 \mathrm{pg} / \mathrm{mL}$-interquartile range 151.0, at baseline) (Fig. 3). In particular, serum PTH levels decreased within the reference range in only $4 / 28$ and $3 / 28$ patients at 6 and 12 months, respectively.

\section{Markers of bone turnover}

Bone turnover was indirectly determined by the measurement of formation (BALP) and resorption (DPD) markers.

Both BALP and urinary DPD were not significantly changed after 1 year of cinacalcet treatment and remained within the normal range for the duration of the study (mean BALP: $20.2 \mu \mathrm{g} / \mathrm{L}$ at baseline and $20.3 \mu \mathrm{g} / \mathrm{L}$ at 12 months; mean UrDPD/UrCr: $6.4 \mathrm{nmol} / \mathrm{mmol}$ at baseline and $6.8 \mathrm{nmol} / \mathrm{mmol}$ at 12 months).

\section{Pituitary and gastroenteropancreatic hormones}

The levels of pituitary hormones were followed up in a subset of patients (\#28) at 12 months, since 5 patients refused or were not compliant to undergo a complete biochemical evaluation at the fixed time points.

In general, no significant changes were observed for any of the pituitary (PRL, IGF1, ACTH) and gastroenteropancreatic hormones (gastrin, glucagon, insulin, VIP, PP, chromogranin A) (Table 2).

At baseline, the levels of pituitary hormones and related peptides were within the reference range (namely, mean $\mathrm{PRL}=381.6 \pm 96.4 \mathrm{mU} / \mathrm{L}, \quad$ ACTH $=17.4 \pm 3.0 \mathrm{ng} / \mathrm{L}$, cortisol $=321.3 \pm 55.9 \mathrm{ng} / \mathrm{L} \quad \mathrm{IGF} 1=196.0 \pm 25.0 \mathrm{ng} /$ $\mathrm{mL})$.

After 12 months of Cinacalcet administration, no significant changes in PRL, IGF1, ACTH, and cortisol levels were detected, although a mean $18 \%$ reduction in PRL values was observed (Table 2).

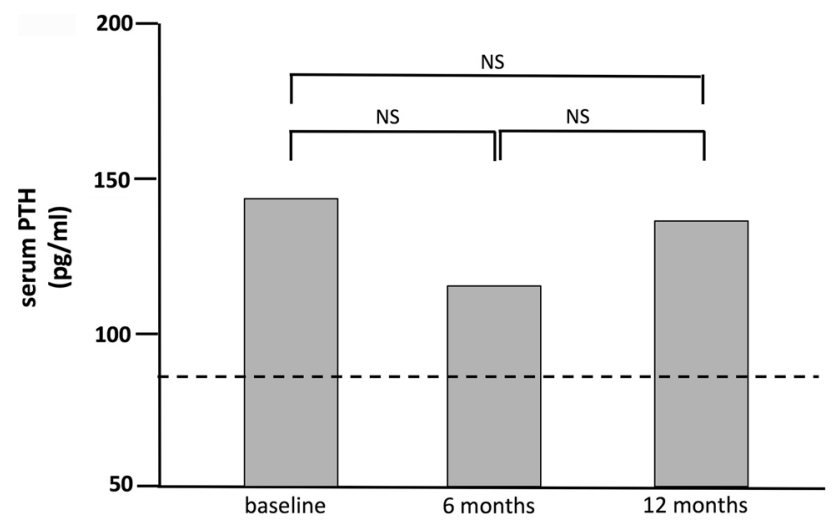

Fig. 3 Changes in median serum PTH levels at 0, 6 months, and 12 months of Cinacalcet treatment in \#33 MEN1 patients; interquartile ranges were $151.0,119.5$, and 90.6 at 0,6 , and 12 months, respectively) (NS non-significant)
Regarding gastroenteropancreatic hormones, baseline levels of chromogranin A, gastrin, PP, and VIP were elevated $(265.0 \pm 97.9 \mathrm{ng} / \mathrm{mL}, 150.8 \pm 65.4 \mathrm{pg} / \mathrm{mL}, 289.3 \pm 160.0 \mathrm{pg} / \mathrm{mL}$, and $31.9 \pm 14.1 \mathrm{pg} / \mathrm{mL}$, respectively), while levels of glucagon and insulin were within the normal range (178.9 \pm $29.2 \mathrm{pg} / \mathrm{mL}$, and $9 \pm 1.39 .4 \mathrm{mU} / \mathrm{L}$, respectively).

As shown in the Table 2, after 1 year of follow-up under Cinacalcet treatment, no significant changes in mean levels of gastrin, PP, glucagon, VIP, or insulin were observed. However, a 49 and $47 \%$ reduction in mean PP and VIP levels, respectively, were detected.

\section{Bone mineral density assessment}

At baseline the majority $(54.5 \%)$ of patients show osteopenia at lumbar spine, while few patients $(33.3 \%)$ were osteoporotic (mean BMD $0.876 \pm 0.165 \mathrm{~g} / \mathrm{cm}^{2}$; T-score $-1.97 \pm 1.51 ; \mathrm{Z}$-score $-1.73 \pm 1.41)$ and total hip (mean BMD $0.806 \pm 0.114 \mathrm{~g} / \mathrm{cm}^{2}$; T-score $-1.51 \pm$ 1.03 ; Z-score $-1.27 \pm 0.95$ ).

No patient received additional therapies influencing bone mass such as bisphosphonates, estrogens, or selective estrogen receptors modulators (SERMs) for the entire period of the study.

No significant changes in BMD and T-score and Z-score values were observed after 12 months of Cinacalcet treatment (Table 2).

\section{Neck ultrasound and parathyroid scintigraphy}

Neck ultrasound performed at baseline showed the presence of parathyroid enlargement in \#27/33 patients, in whom 1-2 glands (sizes ranging from $7 \mathrm{~mm}$ to $30 \mathrm{~mm}$ ) were identified. After 12 months of Cinacalcet therapy the size and ultrasound features of the lesions identified remained unchanged compared with the ultrasound images obtained before treatment.

Similarly, parathyroid scintigraphy at baseline confirmed hyperfunctioning parathyroid tissue (in \#21/33 subjects) and remained unchanged at 12 months.

\section{Safety and tolerability}

No serious AE was reported and no patient displayed hypocalcemia. Therefore, all patients continued Cinacalcet treatment and completed the 12-month follow-up. AEs most commonly reported were heartburn and nausea of I grade, which occurred in five patients who were then treated with proton pump inhibitors until the end of the study, and maintained under the lowest tolerated dosage of Cinacalcet $(30 \mathrm{mg} / \mathrm{dL})$. 
Table 2 Mean levels $( \pm$ SD) of ionized calcium, urinary calcium, pituitary and GEP hormones, markers of bone turnover and BMD at baseline and after 12 months of Cinacalcet treatment in \#28 MEN1 patients (NS nonsignificant)

\begin{tabular}{|c|c|c|c|}
\hline & Baseline & +12 months & $p$ \\
\hline Ionized calcium $(\mathrm{mg} / \mathrm{dL})^{\mathrm{a}}$ & $5.8 \pm 0.3$ & $5.14 \pm 0.33$ & $p<0.001$ \\
\hline Ur calcium $(\mathrm{mg} / 24 \mathrm{~h})^{\mathrm{a}}$ & $330.2 \pm 146.6$ & $245.6 \pm 76.5$ & NS \\
\hline PRL $(\mathrm{mU} / \mathrm{L})^{\mathrm{b}}$ & $381.6 \pm 333.9$ & $309.3 \pm 241.7$ & NS \\
\hline $\mathrm{IGF} 1(\mathrm{ng} / \mathrm{mL})^{\mathrm{b}}$ & $196.0 \pm 86.7$ & $202.6 \pm 87.4$ & NS \\
\hline $\mathrm{ACTH}(\mathrm{ng} / \mathrm{L})^{\mathrm{b}}$ & $17.4 \pm 10.5$ & $17.2 \pm 8.9$ & NS \\
\hline Gastrin $(\mathrm{pg} / \mathrm{mL})^{\mathrm{b}}$ & $150.8 \pm 226.6$ & $155.1 \pm 236.0$ & NS \\
\hline Glucagon $(\mathrm{pg} / \mathrm{mL})^{\mathrm{b}}$ & $178.9 \pm 178.9$ & $250.4 \pm 125.0$ & NS \\
\hline Insulin $(\mathrm{mU} / \mathrm{mL})^{\mathrm{b}}$ & $9.0 \pm 4.5$ & $8.0 \pm 3.9$ & NS \\
\hline $\operatorname{VIP}(\mathrm{pg} / \mathrm{mL})^{\mathrm{b}}$ & $31.9 \pm 25.3$ & $16.9 \pm 8.2$ & NS \\
\hline $\mathrm{PP}(\mathrm{pg} / \mathrm{mL})^{\mathrm{b}}$ & $289.3 \pm 133.4$ & $147.6 \pm 138.9$ & NS \\
\hline chromogranin $\mathrm{A}(\mathrm{ng} / \mathrm{mL})^{\mathrm{b}}$ & $265.0 \pm 220.5$ & $276.8 \pm 138.9$ & NS \\
\hline $\operatorname{BALP}(\mu \mathrm{g} / 1)^{\mathrm{a}}$ & $20.2 \pm 5.3$ & $20.3 \pm 5.5$ & NS \\
\hline $\mathrm{UrDPD} / \mathrm{UrCr}(\mathrm{nmol} / \mathrm{mmol})^{\mathrm{a}}$ & $6.4 \pm 1.9$ & $6.8 \pm 1.7$ & NS \\
\hline lumbar BMD $\left(\mathrm{g} / \mathrm{cm}^{2}\right)^{\mathrm{a}}$ & $0.876 \pm 0.165$ & $0.855 \pm 0.131$ & NS \\
\hline lumbar T-score ${ }^{\mathrm{a}}$ & $-1.97 \pm 1.51$ & $-1.69 \pm 1.00$ & NS \\
\hline lumbar Z-score ${ }^{\mathrm{a}}$ & $-1.73 \pm 1.41$ & $-1.46 \pm 1.34$ & NS \\
\hline total hip BMD $\left(\mathrm{g} / \mathrm{cm}^{2}\right)^{\mathrm{a}}$ & $0.806 \pm 0.114$ & $0.777 \pm 0.126$ & NS \\
\hline total hip T-score ${ }^{\mathrm{a}}$ & $-1.51 \pm 1.03$ & $-1.40 \pm 1.62$ & NS \\
\hline total hip Z-score ${ }^{\mathrm{a}}$ & $-1.27 \pm 0.95$ & $-1.41 \pm 0.96$ & NS \\
\hline
\end{tabular}

a As determined in \#33 patients

b As determined in \#28 patients

\section{Discussion}

PHPT is uncommon in adolescents and young adults, and the majority of these cases occurs as part of congenital forms of PHPT and are associated with multiglandular parathyroid disease, most commonly MEN1 syndrome [13]. PHPT is the most common endocrinopathy in MEN1 syndrome, with high penetrance, and carriers of a mutant gene can now be identified when they are still asymptomatic and can, therefore, be monitored for the development of symptoms and complications of this endocrinopathy [2]. In these patients, sub-total or total parathyroidectomy is associated, respectively, to high recurrence rates and high surgical morbidity for the development of permanent secondary hypoparathyroidism and laryngeal nerve damage [5, 8]. Although it appears that there is no alternative to surgery to achieve a cure for PHPT in MEN1 patients, the need for alternative non-invasive early treatment of PHPT is urgently felt.

Cinacalcet, a calcimimetic, is a potential medical alternative for adult patients with PHPT. It is well established that Cinacalcet, a drug able to sensitize CaSR to extracellular calcium, is a treatment option for patients affected by SHPT and PHPT [18-20].

Although PHPT in MEN1 patients are excellent candidates for a pharmacological treatment, the effectiveness of Cinacalcet in MEN1 has hardly been investigated [25]. In fact, only two different prospective studies and one retrospective data collection have described the efficacy of Cinacalcet in a total of 23 [22, 23] and 32 [24] MEN1 patients affected by PHPT, respectively. In these studies, the mean Cinacalcet dose required to normalize serum calcium did not significantly differ between MEN1 and sporadic PHPT patients, with mild adverse events being experienced by a few patients, requiring the withdrawal of the drug in just two cases within the cumulative total of the treated patients (due to intolerable gastrointestinal side effects and symptomatic hypocalcemia, respectively) [2224]. Based on these results, in the recently published Proceedings of the Fourth International Workshop on Asymptomatic Hyperparathyroidism, Cinacalcet is recognized as a treatment option in patients affected by familial PHPT who have persistent or recurrent hypercalcemia after parathyroidectomy, although it is not recommended as initial therapy for these patients [25].

This prospective study confirms that Cinacalcet is effective and overall safe for the control of hypercalcemia in patients with MEN1-related PHPT. Although another study has previously assessed the effect of this drug on MEN1related primary hyperparathyroidism [22], our study is original since it extends the observation to (1) morphology of parathyroid adenomatous glands; (2) the function of pituitary and gastroenteropancreatic endocrine tissue; and (3) longterm bone safety. As a result, this is the first longitudinal 
study assessing the effect of cinacalcet in MEN1-related primary manifestations, including also neuroendocrine and pituitary tumors. Thus, it is the first study which assess Cinacalcet effectiveness and safety in the whole MEN1 syndrome, although in the limited period of 1-year.

In agreement with previous studies, normocalcemia was achieved in all patients under proper dosage of Cinacalcet in the long term. Cinacalcet safety and tolerability in MEN1 patients was confirmed, since the withdrawal of the drug for serious adverse events was not required in any patient, and only $15 \%$ of the subjects experienced mild upper gastrointestinal side effects, which did not require discontinuation. Under proper titration of Cinacalcet, hypocalcemia was not observed in any patient. This proportion was even lower than the percentage (22\%) reported in the retrospective study by Saponaro et al. [24].

An important question that remains to be answered is the long-term effect of Cinacalcet on a parathyroid tissue constitutively destined to exhibit a high proliferative rate, as happens in MEN1. Previous studies clearly showed that reduced expression of CaSR or Cinacalcet suppressed parathyroid cell proliferation and induced parathyroid cell apoptosis in rodent animal models of PHPT and SHPT [2632]. In this regard, this study for the first time has assessed parathyroid size, which remained unchanged in MEN1 patients under Cinacalcet, as previously shown in patients with sporadic PHPT.

Cinacalcet treatment significantly reduced PTH levels were normalized in a majority of patients analyzed in studies with MEN1-related PHPT patients [22, 23], while the recent retrospective analysis by Saponaro et al. has shown that PTH levels did not significantly change with respect to baseline levels in a wider group of patients with MEN1-PHPT [24], as confirmed in our study. At the same time, the decreases of the hormone obtained by Cinacalcet in familial PHPT were enhanced when compared to sporadic PHPT [24]. The reason for this enhanced PTH response in MEN1 is not clear, and the possibility of the underlying pathogenesis (hyperplasia vs. adenoma) or a different expression of the CaSR representing the answers requires further investigation.

Even if CaSR is expressed in pituitary and gastroenteropancreatic endocrine cells [33-38], two typical endocrine tissues involved in MEN1, a full biochemical and hormonal profile was not performed in the above mentioned studies, with the exception of the first MEN1 case we treated with Cinacalcet [21]. In this prospective study, gastroenteropancreatic and pituitary hormones were, for the first time, assessed in a wide group of patients with MEN1 under Cinacalcet treatment, and no significant changes toward baseline were demonstrated.

Until now, the lack of safety data of long-term Cinacalcet treatment on bone safety in MEN1 patients has been an important limitation [39]. Here, we show for the first time that effective Cinacalcet treatment was not detrimental to bone in MEN1 patients, since no significant changes were observed in either trabecular or cortical $\mathrm{BMD}$, as represented by lumbar spine and proximal femur, respectively. Unfortunately, measurements at the distal one-third of the radius, which represents a sites predominantly constituted by cortical bone particularly hampered by PTH excess, were not performed in this study and this may constitute a limit to our study.

Previously published data highlighted the theoretical concern of increased Cinacalcet-induced urinary calcium excretion, due to the direct action of CaSR in the kidney, even if the overall reduction in serum calcium appears to counteract this effect [20]. In view of this theoretical concern, 24-h urine calcium levels were assessed in this study and were not altered by Cinacalcet administration, as reported in previous studies [23, 24].

Finally, the possibility of using Cinacalcet in the prevention of PHPT in asymptomatic MEN1 patients could also be considered, as happens in other endocrine tumors in MEN1. Indeed, bromocriptine and cabergoline are commonly used in hyperprolactinemia in MEN1 $(1,2)$, and recently somatostatin analogs were reported as efficacious in the control of neuroendocrine tumor function and proliferation in MEN1 patients [40]. In general, pharmacological treatments in MEN1 hormone secreting tumors is less effective than in the sporadic counterparts, but it may serve to postpone surgical treatment until later in life. Future studies should address these questions, also for asymptomatic hyperparathyroidism in MEN1 patients.

\section{Conclusions}

In conclusion, this study confirms the efficacy and safety profile of Cinacalcet in patients with MEN1-related PHPT, with improvements in serum calcium, and without modification of parathyroid tissue size. Due to the high recurrence rate of PHPT in MEN1 patients, Cinacalcet should represent a second choice treatment option for calcium normalization in these patients. The possibility to offer a pharmacological treatment to prevent the progression of PHPT in MEN1 patients would require global, double-blind, randomized, placebo-controlled trials and appropriate pharmacoeconomic analyses to evaluate clinical effectiveness, safety, and tolerability of longterm Cinacalcet treatment of young hyperparathyroid subjects.

Acknowledgments This study was supported by an unrestricted grant from Amgen. 


\section{Compliance with ethical standards}

Conflict of interest All Authors have no conflict of interest to declare regarding this paper. More general disclosures for P.F.: Advisory Board for Novartis, Ipsen, Lexicon, and Italfarmaco. More general disclosures for M.L.B.: consultant and grants from Alexion, Abiogen, Amgen, Bruno Farmaceutici, Eli Lilly, MSD, NPS, Shire, SPA, and Servier.

Ethical approval All procedures performed in studies involving human participants were in accordance with the ethical standards of the institutional and/or national research committee and with the 1964 Helsinki declaration and its later amendments or comparable ethical standards.

Informed consent Informed consent was obtained from all individual participants included in the study.

\section{References}

1. M.L. Brandi, R.F. Gagel, A. Angeli et al., Consensus: guidelines for diagnosis and therapy of MEN type 1 and type 2. J. Clin. Endocrinol. Metab. 86, 5658 (2001)

2. R.V. Thakker, P.J. Newey, G.V. Walls, J. Bilezikian, H. Dralle, P.R. Ebeling, S. Melmed, A. Sakurai, F. Tonelli, M.L. Brandi, Endocrine Society. Clinical practice guidelines for multiple endocrine neoplasia type 1 (MEN1). J. Clin. Endocrinol. Metab. 97, 2990 (2012)

3. Giusti, F., Marini, F., Brandi, M. L.: Multiple endocrine neoplasia type 1. In: GeneReviews at GeneTests: Medical Genetics Information Resource [database online]. Copyright, University of Washington, Seattle, 1997-2005. http://www.ncbi.nlm.nih.gov/ books/NBK1538; initial posting: August 31, 2005; last updated: September 6, 2012

4. T. Carling, R. Udelsman, Parathyroid surgery in familial hyperparathyroid disorders. J. Intern. Med. 257, 27 (2005)

5. F. Tonelli, T. Marcucci, G. Fratini, M.S. Tommasi, A. Falchetti, M.L. Brandi, Is total parathyroidectomy the treatment of choice for hyperparathyroidism in multiple endocrine neoplasia type 1 ? Ann. Surg. 246, 1075 (2007)

6. D.M. Elaraj, M.C. Skarulis, S.K. Libutti, J.A. Norton, D.L. Bartlett, J.F. Pingpank, F. Gibril, L.S. Weinstein, R.T. Jensen, S.J. Marx, H.R. Alexander, Results of initial operation for hyperparathyroidism in patients with multiple endocrine neoplasia type 1. Surgery 134, 858 (2003)

7. E.M. Brown, The calcium-sensing receptor: physiology, pathophysiology and CaR-based therapeutics. Subcell. Biochem. 45, 139 (2007)

8. E.F. Nemeth, M.E. Steffey, L.G. Hammerland, B.C. Hung, B.C. Van Wagenen, E.G. DelMar, M.F. Balandrin, Calcimimetics with potent and selective activity on the parathyroid calcium receptor. Proc. Natl. Acad. Sci. USA 95, 4040 (1998)

9. E.F. Nemeth, J. Fox, Calcimimetic compounds: a direct approach to controlling plasma levels of parathyroid hormone in hyperparathyroidism. Trends Endocrinol. Metab. 10, 66 (1999)

10. J.S. Lindberg, S.M. Moe, W.G. Goodman, J.W. Coburn, S.M. Sprague, W. Liu, P.W. Blaisdell, R.M. Brenner, S.A. Turner, K.J. Martin, The calcimimetic AMG 073 reduces parathyroid hormone and calcium $\mathrm{x}$ phosphorus in secondary hyperparathyroidism. Kidney Int. 63, 248 (2003)

11. L.D. Quarles, D.J. Sherrard, S. Adler, S.J. Rosansky, L.C. McCary, W. Liu, S.A. Turner, D.A. Bushinsky, The calcimimetic AMG 073 as a potential treatment for secondary hyperparathyroidism of endstage renal disease. Jam Soc Nephrol 14, 575 (2003)
12. D.M. Shoback, J.P. Bilezikian, S.A. Turner, L.C. McCary, M.D. Guo, M. Peacock, The calcimimetic Cinacalcet normalizes serum calcium in subjects with primary hyperparathyroidism. J. Clin. Endocrinol. Metab. 88, 5644 (2003)

13. M. Peacock, J.P. Bilezikian, P.S. Klassen, M.D. Guo, S.A. Turner, D. Shoback, Cinacalcet Hydrochloride Maintains LongTerm Normocalcemia in Patients with Primary Hyperparathyroidism. J. Clin. Endocrinol. Metabol. 90, 135 (2005)

14. A. Khan, J. Bilezikian, H. Bone, A. Gurevich, P. Lakatos, W. Misiorowski, L. Rozhinskaya, M.L. Trotman, M. Tóth, Cinacalcet normalizes serum calcium in a double-blind randomized, placebo-controlled study in patients with primary hyperparathyroidism with contraindications to surgery. Eur. J. Endocrinol. 172, 527 (2015)

15. European Medicines Agency, Assessment report for cinacalcet $\left(\right.$ Mimpara $\left.^{\circledR}\right)$, Procedure No. EMEA/H/C/000570/II/0010: http:// www.ema.europa.eu/docs/en_GB/document_library/EPAR_-_ Assessment_Report_-_Variation/human/000570/WC500028903. pdf (2008)

16. Federal Drug Administration (FDA), Report for cinacalcet (Sensipar®): http://www.accessdata.fda.gov/drugsatfda_docs/ label/2011/021688s017lbl.pdf (2011)

17. FDA drug safety communivication: http://www.fda.gov/Drugs/ DrugSafety/ucm340551.htm

18. EMA, cinacalcet, Annex I, summary of product characteristics http://www.ema.europa.eu/docs/en_GB/document_library/EPAR_-Product_Information/human/000570/WC500028900.pdf (2013)

19. J.A. Balfour, L.J. Scott, Cinacalcet hydrochloride. Drugs 65, 271 (2005)

20. M.S. Joy, A.V. Kshirsagar, N. Franceschini, Calcimimetics and the treatment of primary and secondary hyperparathyroidism. Ann. Pharmacother. 38, 1871 (2004)

21. A. Falchetti, A. Cilotti, L. Vagelli, L. Masi, A. Amedei, F. Cioppi, F. Tonelli, M.L. Brandi, A patient with MEN1-associated hyperparathyroidism, responsive to Cinacalcet. Nat. Clin. Pract. Endocrinol. Metab. 4, 351 (2008)

22. V.J. Moyes, J.P. Monson, S.L. Chew, S.A. Akker, Clinical Use of Cinacalcet in MEN1 Hyperparathyroidism. Int. J. Endocrinol. 2010, 906163 (2010)

23. M. Filopanti, U. Verga, F. Ermetici, L. Olgiati, C. Eller-Vainicher, S. Corbetta, L. Persani, P. Beck-Peccoz, A. Spada, MEN1-related hyperparathyroidism: response to cinacalcet and its relationship with the calcium-sensing receptor gene variant Arg990Gly. Eur. J. Endocrinol. 167, 157 (2012)

24. F. Saponaro, A. Faggiano, F. Grimaldi, G. Borretta, M.L. Brandi, S. Minisola, A. Frasoldati, E. Papini, A. Scillitani, C. Banti, M. Del Prete, F. Vescini, L. Gianotti, L. Cavalli, E. Romagnoli, A. Colao, F. Cetani, C. Marcocci, Cinacalcet in the management of primary hyperparathyroidism: post marketing experience of an Italian multicentre group. Clin. Endocrinol. 79, 20 (2013)

25. C. Marcocci, J. Bollerslev, A.A. Khan, D.M. Shoback, Medical management of primary hyperparathyroidism: proceedings of the fourth International Workshop on the Management of Asymptomatic Primary Hyperparathyroidism. J. Clin. Endocrinol. Metab. 99, 3607 (2014)

26. C. Ho, D.A. Conner, M.R. Pollak, D.J. Ladd, O. Kifor, H.B. Warren, E.M. Brown, J.G. Seidman, C.E. Seidman, A mouse model of human familial hypocalciuric hypercalcemia and neonatal severe hyperparathyroidism. Nat. Genet. 11, 389 (1995)

27. M. Colloton, E. Shatzen, G. Miller, C. Stehman-Breen, M. Wada, D. Lacey, D. Martin, Cinacalcet $\mathrm{HCl}$ attenuates parathyroid hyperplasia in a rat model of secondary hyperparathyroidism. Kidney Int. 67, 467 (2005)

28. T. Kawata, Y. Imanishi, K. Kobayashi, T. Kenko, M. Wada, E. Ishimura, T. Miki, N. Nagano, M. Inaba, A. Arnold, Y. Nishizawa, Relationship between parathyroid calcium-sensing receptor 
expression and potency of the calcimimetic, cinacalcet, in suppressing parathyroid hormone secretion in an in vivo murine model of primary hyperparathyroidism. Eur. J. Endocrinol. 153, 587 (2005)

29. N. Wettschureck, E. Lee, S.K. Libutti, S. Offermanns, P.G. Robey, A.M. Spiegel, Parathyroid-specific double knockout of $\mathrm{Gq}$ and G11 alpha-subunits leads to a phenotype resembling germline knockout of the extracellular $\mathrm{Ca}^{2+}$-sensing receptor. Mol. Endocrinol. 21, 274 (2007)

30. Y. Imanishi, M. Inaba, T. Kawata, Y. Nishizawa, Animal models of hyperfunctioning parathyroid diseases for drug development. Exp. Opin. Drug Discov. 4, 727 (2009)

31. K. Weber, C. Bergow, S. Hirmer, C. Schüler, R.G. Erben, Vitamin D-independent therapeutic effects of extracellular calcium in a mouse model of adult-onset secondary hyperparathyroidism. J. Bone Miner. Res. 24, 22 (2009)

32. Y. Imanishi, T. Kawata, T. Kenko, M. Wada, N. Nagano, T. Miki, A. Arnold, M. Inaba, Cinacalcet $\mathrm{HCl}$ suppresses Cyclin D1 oncogene-derived parathyroid cell proliferation in a murine model for primary hyperparathyroidism. Calcif. Tissue Int. 89, 29 (2011)

33. M.N. Hodgkin, C.E. Hills, P.E. Squires, The calcium-sensing receptor and insulin secretion: a role outside systemic control 15 years on. J. Endocrinol. 199, 1 (2008)

34. J. Parkash, Inflammatory cytokine signaling in insulin producing beta-cells enhances the colocalization correlation coefficient between L-type voltage-dependent calcium channel and calciumsensing receptor. Int. J. Mol. Med. 22, 155 (2008)
35. I. Kitsou-Mylona, C.J. Burns, P.E. Squires, S.J. Persaud, P.M. Jones, A role for the extracellular calcium-sensing receptor in cell-cell communication in pancreatic islets of langerhans. Cell. Physiol. Biochem. 22, 557 (2008)

36. D. Haid, P. Widmayer, H. Breer, Nutrient sensing receptors in gastric endocrine cells. J. Mol. Histol. 42, 355 (2011)

37. J.M. Ray, P.E. Squires, S.B. Curtis, M.R. Meloche, A.M. Buchan, Expression of the calcium-sensing receptor on human antral gastrin cells in culture. J. Clin. Invest. 99, 2328 (1997)

38. R. Mamillapalli, J. Wysolmerski, The calcium-sensing receptor couples to Galpha(s) and regulates PTHrP and ACTH secretion in pituitary cells. J. Endocrinol. 204, 287 (2010)

39. M. Peacock, M.A. Bolognese, M. Borofsky, S. Scumpia, L.R. Sterling, S. Cheng, D. Shoback, Cinacalcet treatment of primary hyperparathyroidism: biochemical and bone densitometric outcomes in a five-year study. J. Clin. Endocrinol. Metab. 94, 4860 (2009)

40. V. Ramundo, M. Del Prete, V. Marotta, F. Marciello, L. Camera, V. Napolitano, L. De Luca, L. Circelli, V. Colantuoni, A. Di Sarno, A.C. Carratù, C. de Luca di Roseto, A. Colao, A. Faggiano, Multidisciplinary Group for Neuroendocrine Tumors of Naples: Impact of long-acting octreotide in patients with early-stage MEN1-related duodeno-pancreatic neuroendocrine tumours. Clin. Endocrinol. 80, 850 (2014) 